\title{
Quantitative volumetric assessment of the solid portion percentage on CT images to predict ROS1/ALK rearrangements in lung adenocarcinomas
}

\author{
JING ZHENG $^{1 *}$, JIANYA ZHOU $^{1 *}$, JINPENG LIU ${ }^{2}$, JINGFENG XU $^{2}, \mathrm{KE} \mathrm{SUN}^{3}$, \\ BO WANG ${ }^{3}, \mathrm{HE} \mathrm{CAO}^{1}$, WEI DING ${ }^{3}$ and JIANYING ZHOU ${ }^{1}$
}

${ }^{1}$ Department of Respiratory Disease, Thoracic Disease Center, The First Affiliated Hospital, College of Medicine; Departments of ${ }^{2}$ Radiology and ${ }^{3}$ Pathology, The First Affiliated Hospital, College of Medicine, Zhejiang University, Hangzhou, Zhejiang 310003, P.R. China

Received December 11,2019; Accepted May 27, 2020

DOI: $10.3892 / \mathrm{ol} .2020 .11816$

\begin{abstract}
In the present study, the predictive role of the percentage of the solid portion volume (PSV) in patients with lung adenocarcinoma was investigated. The PSV was obtained through quantitative volumetric assessments based on reconstructed CT images of lung adenocarcinoma by comparing the index among tumors with c-ros oncogene 1 (ROS1) rearrangement, epidermal growth factor receptor (EGFR) mutations, echinoderm anaplastic lymphoma kinase (ALK) rearrangements or wild-type (WT) status for the three genes. Among 1,120 patients with lung adenocarcinoma, 28 patients with ROS1 rearrangement lung adenocarcinoma, 71 with ALK rearrangement and 578 with EGFR mutations were diagnosed. PSV was quantitatively measured by semi-automated nodule assessment software and compared in patients with different mutation statuses. The PSV (presented as the median with interquartile range) in the ROS1 rearrangement group [87.9 (82.7-92.3)\%] was higher than that in the EGFR mutation group [70.4 (51.4-83.4\%)] and the WT group [63.0 (50.9-83.2)\%; $\mathrm{P}<0.001]$, but was similar to that in the ALK rearrangement group [84.0 (70.3-90.0)\%; $\mathrm{P}=0.251$ ]. The area under the receiver operating characteristic curve (AUC) for the PSV to predict ROS1 or ALK rearrangement combined was 0.702 (95\% CI: 0.631-0.773; $\mathrm{P}<0.001$ ); at a cut-off value of 0.805 (when the Youden index was maximal), the predictive sensitivity was 0.697 and the specificity was 0.702 . Younger age and higher PSV values were
\end{abstract}

Correspondence to: Professor Jianying Zhou, Department of Respiratory Disease, Thoracic Disease Center, The First Affiliated Hospital, College of Medicine, Zhejiang University, 79 Qingchun Road, Shangcheng, Hangzhou, Zhejiang 310003, P.R. China

E-mail: zjyhz@zju.edu.cn

*Contributed equally

Key words: c-ros oncogene 1, anaplastic lymphoma kinase, epidermal growth factor receptor, CT, lung adenocarcinoma independent predictors of ROS1/ALK rearrangements. The AUC for the predictive model combined with age and PSV was 0.785 . In conclusion, the PSV in the lung adenocarcinomas with ROS1 rearrangement was significantly higher compared with that in the EGFR-mutated and WT lung adenocarcinoma, but was similar to that in lung adenocarcinoma with ALK rearrangement. Younger age and higher PSV values on CT in patients with lung adenocarcinomas were predictive factors for ROS1/ALK rearrangement.

\section{Introduction}

The discovery and use of tyrosine kinase inhibitors (TKI) specifically targeting epidermal growth factor receptor (EGFR) in the management of non-small-cell lung cancer (NSCLC) in 2004 spearheaded the development of the molecular pathology classification for lung cancer and targeted therapies $(1,2)$. Soda et al (3) revealed the presence of a hybrid gene borne as a result of anaplastic lymphoma kinase (ALK) gene chromosomal rearrangement. Furthermore, Rikova et al (4) characterized c-ros oncogene 1 (ROS1) rearrangement in NSCLC tumors. The molecular pathology-based classification has significantly increased the efficacy of targeted tyrosine kinase inhibitors in comparison with standard chemotherapy.

Crizotinib is an ALK TKI and was successful in gaining approval as a therapeutic agent for advanced NSCLCs with ALK and ROS1 rearrangement (5-8). Indeed, ALK and ROS1 genes share similar properties in terms of their amino acid sequence of the kinase domain and the adenosine triphosphate binding site. This similarity provided a basis for the properties of crizotinib in combating NSCLCs that possess these gene fusions. The phase I PROFILE 1001 study of crizotinib included 50 patients with ROS1-rearranged NSCLC who achieved a median progression-free survival (PFS) of 19.3 months and a median overall survival (OS) of 51.4 months with crizotinib treatment, with an objective response rate of $72 \%$ (8). This efficacy rate was much better than that for traditional chemotherapy, further highlighting the importance of genetic mutation detection in guiding NSCLC treatment. However, limited tissue samples are usually obtained, given 
the extremely invasive procedures necessary to procure them (lung biopsy and bronchoscopy). This reason coupled with the high cost of genetic testing frequently lead to numerous patients not undergoing genetic testing at all. Furthermore, testing for ROS1 rearrangements is frequently not performed, as they have been detected in only a low proportion of patients with NSCLC (0.9-2\%). Therefore, there is an urgent requirement for a non-invasive and low-cost method to distinguish ROS1/ALK-rearranged patients from EGFR-mutated or wild-type (WT) patients to facilitate the selection of individualized treatment strategies. In this regard, it has been indicated that the clinical and imaging characteristics of patients with NSCLC may be able to predict their genetic status.

ALK rearrangements are typically encountered in patients with lung adenocarcinoma. These patients frequently have no history or a history of light smoking and are generally young (9-12). Solid-pattern growth on CT, an elevated glucose metabolism on positron-emission tomography (PET)/CT and relatively more rapid metastasis to lymph nodes or distant sites on PET/CT have been reported to be the primary radiological features of ALK-rearranged tumors compared with non-ALK-rearranged tumors in previous studies (12-14). A previous study by our group has highlighted the different imaging features between ALK-rearranged NSCLC, EGFR-mutated NSCLC and WT NSCLC, and noted that solid patterns were the predominant distinct features of ALK-rearranged tumors compared with other tumors (13).

In addition to ALK rearrangement, ROS1 rearrangement detection and targeted therapies have also been studied. Several studies have discussed the clinical and pathological features of NSCLC tumors with or without ROS1 rearrangement $(15,16)$. There are a number of studies on the radiological characteristics of tumors with ROS1 rearrangement compared with tumors with other gene statuses. Digumarthy et al (17) indicated that ROS1-rearranged tumors more frequently displayed features of lymphangitic carcinomatosis (ROS1-rearranged, 42\%; EGFR-mutated, $12 \%$; $\mathrm{P}<0.01$ ), had a lower chance of developing lymphangitic carcinomatosis and were more likely to have air bronchograms present in the primary tumor (ROS1-rearranged, 2\%; EGFR-mutated, 28\%; $\mathrm{P}<0.01$ ). The above study qualitatively described the radiographic features, while the present study performed a quantitative volumetric analysis to evaluate the imaging features in lung adenocarcinoma with different gene statuses.

The present retrospective study aimed to assess the ability of PSV (also in combination with other clinical parameters) to predict the ROS1/ALK rearrangement status in lung adenocarcinoma in order to facilitate the specific targeted treatment.

\section{Materials and methods}

Patient selection and grouping. All procedures of the present study involving human participants were performed in strict compliance with the ethical standards of the institutional research committee and with the 1964 Helsinki declaration and its later amendments or comparable ethical standards. The ethics committee of the First Affiliated Hospital of Zhejiang University (Hangzhou, China) approved the study and waived the requirement for obtaining informed consent.
For all patients included, CT images had been obtained at the First Affiliated Hospital of Zhejiang University (Hangzhou, China). Clinical data were obtained from the medical records of each patient retrospectively. The TNM classification was also extracted and TNM staging was based on the seventh edition of the Union for International Cancer Control and American Joint Committee on Lung Cancer (18).

Confirmation of ROS1 rearrangement through real-time $P C R$. A $4-\mu \mathrm{m}$ thick formalin-fixed (at $25^{\circ} \mathrm{C}$ for $12-24 \mathrm{~h}$ ), paraffin-embedded (FFPE) tissue slice was used to evaluate ROS1 and ALK gene rearrangement. A total of three 5- $\mu \mathrm{m}$ sections of each tumor were used for total RNA extraction, which was performed based on predefined protocols (19) (RNeasy FFPE kit; Qiagen GmbH). The ROS1 rearrangement status was determined by multiplex real-time PCR in a Stratagene Mx3000P real-time PCR system (Stratagene Corp.) with an AmoyDx ${ }^{\circledR}$ ROS1 fusion gene detection kit (Amoy Diagnostics Co., Ltd.). ROS1 fusion combinations, including SLC34A2-ROS1, EZR-ROS1, CD74-ROS1, SDC4-ROS1, LRIG3-ROS1, TPM3-ROS1 and GOPC-ROS1, were detected in this assessment. The internal reference gene ( $\beta$-actin) was used as a negative control and a confirmed ROS1-rearranged DNA was used as a positive control in the AmoyDx ${ }^{\circledR}$ ROS1 Gene Fusions Detection kit (cat. no. 8.01.23201W012A; Amoy Diagnostics Co., Ltd.).

Confirmation of ALK rearrangement using fluorescence in situ hybridisation (FISH). ALK gene fusion was evaluated with FISH utilizing an ALK break-apart probe (Vysis LSI ALK Dual Color, Break Apart Rearrangement Probe; Abbott Molecular), in accordance with previously published protocols (13).

EGFR mutation analysis using pyrosequencing assay. A PCR-based pyrosequencing assay was used to analyze EGFR mutations located on exons 18-21 (20). The PyroMark system (Qiagen $\mathrm{GmbH}$ ) was used to perform sequence analysis.

CT imaging. Each patient received thoracic CT scans with either the 64-slice Brilliance, 256-slice iCT (Philips Medical Systems, Inc.) or 64-slice light-speed VCT (GE Healthcare). CT scan systems had the following parameters: Rotation speed, 0.5/sec; pitch, $1 ; 120 \mathrm{kV} ; 120-380 \mathrm{~mA}$; field of view, $300-350 \mathrm{~mm}$; and collimation, $0.625 \mathrm{~mm}$. A high-frequency reconstruction algorithm with a $512 \times 512$ matrix was used for image reconstruction. The reconstruction thicknesses and intervals were 5.0 and $5.0 \mathrm{~mm}$, respectively. CT imaging information was reviewed in a Philips CT workstation using the mediastinal window setting [width, 200 Hounsfield Units (HU); level, $40 \mathrm{HU}$ ] and lung window setting (width, 1,500 HU; level, $500 \mathrm{HU}$ ), which were obtained prior to contrast administration.

Interpretations of CT images. All CT images were independently reviewed by JL and JX, two radiologists with 10 years of experience. The radiologists were not blinded to the patients' diagnoses of lung adenocarcinoma but were blinded to their genetic statuses. The presence or absence of multiple lesions, lobulated borders, fine spiculated margins, bubble-like 
lucency, cavity, liquefaction necrosis and air bronchogram were assessed.

Multiple lesions were defined as more than one tumor lesion on a CT scan. A lobulated border was defined as a shallow wavy configuration seen on part of the border of the lesion, excluding lesions that were abutting the pleura $(13,20-22)$. A lesion that possessed fine linear strands extending 1-2 mm radially was defined as having fine spiculated margins. Lesions that possessed air attenuation spots within them were classified as having bubble-like lucency $(13,20)$ and a cavity was defined as a gas-filled space appearing as an area of lower attenuation or lucency (21). A hypodense area on non-enhanced and contrast-enhanced CT images was defined as liquefaction necrosis (23). An air bronchogram was defined as an air-filled (low-attenuation) bronchus against an opaque background (high-attenuation) $(13,21)$.

Quantitative volumetric assessment. Lung nodule reconstruction was performed using the 256-slice iCT (Philips Medical Systems), which allowed for the quantification of the volume of individual lesions. The software is able to automatically generate solid tumor boundaries on each cross-section, while extracting intramodular bronchial and cavitating structures in order to reconstruct a three-dimensional structure of the nodule and provide data on the volume (V) and estimated diameter (D) (Fig. 1). For mixed tumor nodules with solid and ground-glass opacity (GGO) portions (Fig. 2A and B), as well as for the entire nodule (Fig. 2C), all computer-derived boundaries were assessed and adjusted as necessary by the two experienced radiologists. The software reconstructed the three-dimensional structure of the nodule and provided data on the entire nodule and the solid portion (Fig. 2D). The radiologists recorded the volume and the estimated diameter mentioned above for the total nodule $(\mathrm{tV}, \mathrm{tD})$ and the solid portion $(\mathrm{sV}, \mathrm{sD})$. The PSV was calculated using the formula $P S V=s V / t V$.

Statistical analysis. The patients with different gene status' were included in different groups via a simple randomization method (Fig. 3). A Chi-squared test was used to compare categorical variables. For continuous variables, including age, $\mathrm{tV}, \mathrm{tD}$ and PSV, differences in median values between two groups were compared by the Mann-Whitney U-test, while the Kruskal-Wallis U-test was used for comparisons among four groups. The univariate and multivariate logistic regression analyses were performed to predict ROS1/ALK-rearranged. Variates with $\mathrm{P} \leq 0.10$ in the univariate analysis were included in a multivariable logistic regression analysis. A receiver operating characteristic (ROC) analysis was carried out to evaluate the predictive value of PSV and the multi-factor (all independent predictive factors selected by multivariate analysis) predictive model to predict ROS1 rearrangement or ROS1/ALK rearrangement. All statistical analyses were performed using SPSS version 17.0 (SPSS, Inc.). $\mathrm{P}<0.05$ was considered to indicate statistical significance.

\section{Results}

Clinical characteristics of patients with lung adenocarcinoma with different gene statuses. In the present study, 28 ROS1-rearranged, 578 EGFR-mutated and 71

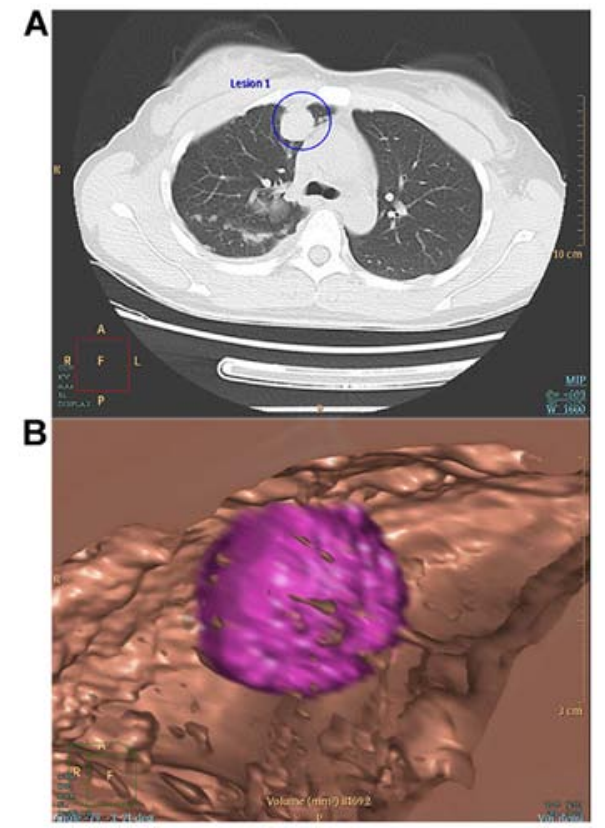

Figure 1. Representative CT and three-dimensional nodule images obtained by the 256-slice iCT which automatically generates (A) solid tumor boundaries and (B) three-dimensional nodule structure reconstruction to record the volume and estimated diameter of the nodule.

ALK-rearranged patients were retrospectively identified among 1,120 patients with histology-confirmed lung adenocarcinoma diagnosed at the First Affiliated Hospital of Zhejiang University (Hangzhou, China) between March 2008 and October 2015. The 28 ROS1-rearranged patients were assigned to the ROS1 rearrangement group (ROS1 rearrangement group or $\mathrm{ROS}^{+}$group; $\mathrm{n}=28$ ). Furthermore, 56 ALK-rearranged patients were randomly selected from the 71 ALK-rearranged patients (ALK rearrangement group or $\mathrm{ALK}^{+}$group; $\mathrm{n}=56$ ), as well as 112 patients with EGFR mutations from the 578 EGFR-mutated patients (EGFR mutation group or $\mathrm{EGFR}^{+}$group; $\mathrm{n=112}$ ) and 112 patients from those who exhibited the WT for all three genes (WT group; $n=112$ ). The patient selection procedure is presented in Fig. 3. The EGFR mutation group included 65 patients with EGFR 19 exon mutation, 44 patients with EGFR 21 exon mutation, 1 patient with EGFR 20 exon mutation, 1 patient with both EGFR 19 and 20 exon mutation and 1 patient with both EGFR 20 and 21 exon mutation.

The demographic and clinicopathological features of the patients with lung adenocarcinoma are presented in Table I. The median age (range) of the patients in the $\mathrm{ROS}^{+}, \mathrm{ALK}^{+}$, $\mathrm{EGFR}^{+}$and WT groups was 54.5 (27-60), 51.0 (23-79), 60.0 (34-83) and 62.0 (31-83) years, respectively. Individuals possessing ROS1 rearrangements were noted to be markedly younger in comparison with those with EGFR mutations $(\mathrm{P}=0.007)$ and patients who did not test positive for all three genes $(\mathrm{P}=0.003)$. Patients with ROS1 mutations were more likely to be female $(\mathrm{P}=0.006)$ in contrast to the WT group. Those who had no history of smoking were also more likely to have ROS1 mutations $(\mathrm{P}=0.005)$ in comparison with the WT group. The demographic features (age, sex and smoking history) of ROS1-rearranged patients were not different compared to those of ALK-rearranged patients. Patients across 

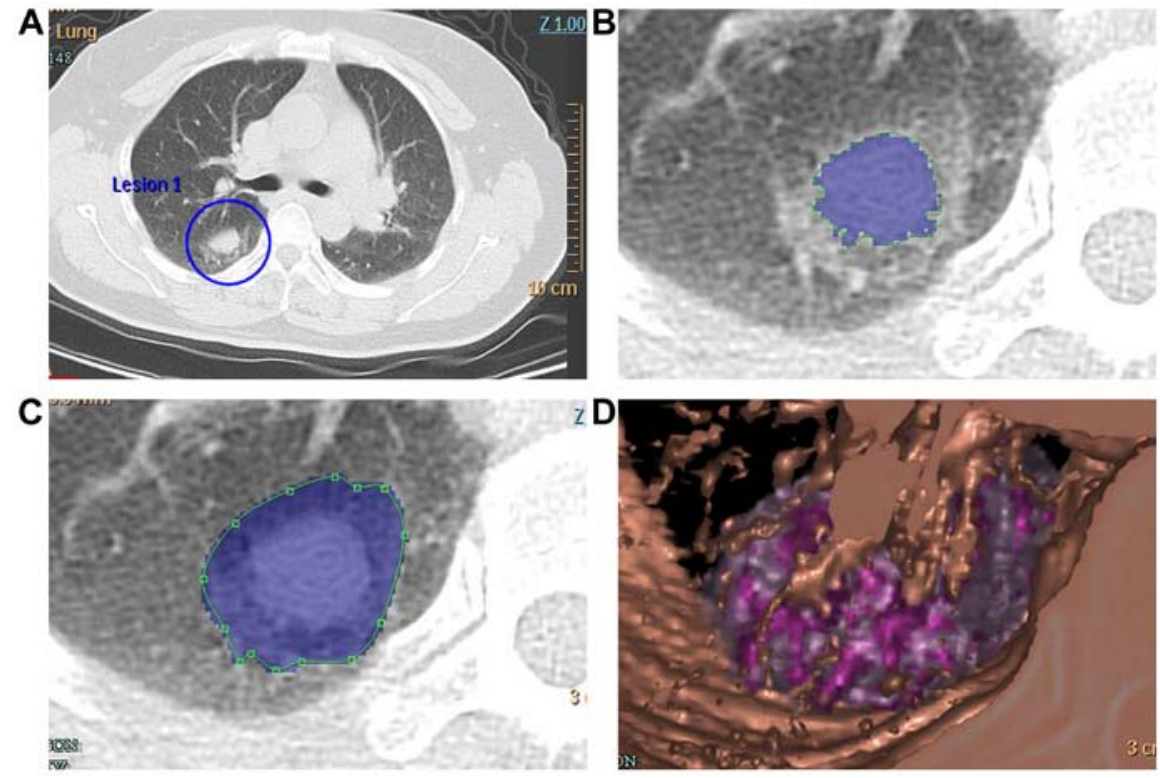

Figure 2. Images displaying the quantitative tumor volumetric assessment of mixed nodules. (A) The software is able to automatically recognize the tumor. (B and C) radiologist-generated boundaries of (B) the solid portion of the tumor and (C) the whole nodule on each section (green lines). (D) The reconstructed three-dimensional image and data of the whole tumor and solid portion were recorded (not shown).

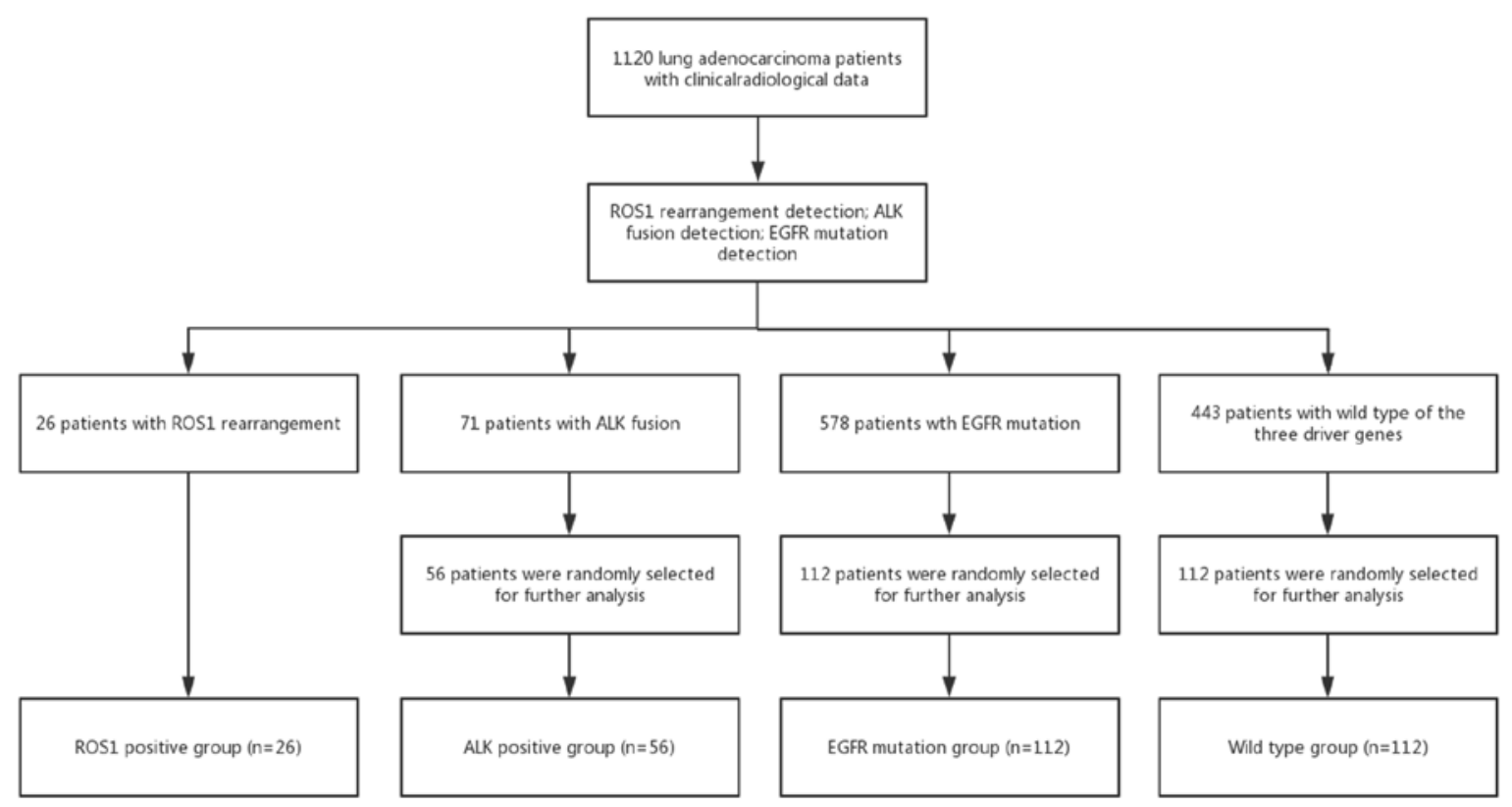

Figure 3. Inclusion criteria and process of patient selection. A total of 1,120 patients were diagnosed with lung adenocarcinomas at our center. ROS1, c-ros oncogene 1; ALK, anaplastic lymphoma kinase; EGFR, epidermal growth factor receptor.

the four groups did not exhibit any notable variability in terms of carcinoembryonic antigen levels.

Comparison of the $t D, t V$ and PSV between tumors with different gene statuses. Fig. 4 provides comparisons of the $\mathrm{tD}, \mathrm{tV}$ and PSV across tumors with various genetic aberrations. The PSV [median (interquartile range)] in tumors with ROS1 rearrangements [87.9 (82.7-92.3) \%] was markedly higher compared with those with EGFR mutations [70.4 (51.4-83.4)\%; $\mathrm{P}<0.001]$ and those of the WT [63.0 (50.9-83.2)\%; $\mathrm{P}<0.001]$. However, the difference in PSV between the ROS1 ${ }^{+}$ group and the $\mathrm{ALK}^{+}$group [84.0 (70.3-90.0)\%; $\left.\mathrm{P}=0.251\right]$ was not significant. There was no difference in the median value of the $\mathrm{tD}$ and $\mathrm{tV}$ among the four groups.

CT images of four representative patients with different genetic status are presented in Fig. 5. The four tumors exhibited different PSV on CT.

The ROC curves for the predictive value of PSV for the gene rearrangements are provided in Fig. 6. The area under the ROC curve (AUC) of PSV to predict ROS1 rearrangement was 0.736 (95\% CI, 0.637-0.835; P<0.001; Fig. 6A) at a cut-off value of 0.849 . When the Youden index was maximal, the sensitivity was 0.750 and the specificity was 0.743 . Given the similar PSV values in the $\mathrm{ROSI}^{+}$group and the $\mathrm{ALK}^{+}$group, a ROC curve 
Table I. Clinical characteristics of the patients based on genetic alterations in lung adenocarcinomas.

\begin{tabular}{|c|c|c|c|c|c|c|c|c|}
\hline \multirow[b]{2}{*}{$\begin{array}{l}\text { Clinical } \\
\text { characteristic }\end{array}$} & \multicolumn{4}{|c|}{ Genetic alteration } & \multicolumn{4}{|c|}{ P-value } \\
\hline & $\begin{array}{l}\mathrm{ROS}^{+} \\
(\mathrm{n}=28)\end{array}$ & $\begin{array}{l}\mathrm{ALK}^{+} \\
(\mathrm{n}=56)\end{array}$ & $\begin{array}{l}\mathrm{EGFR}^{+} \\
(\mathrm{n}=112)\end{array}$ & $\begin{array}{c}\text { WT } \\
(n=112)\end{array}$ & $\begin{array}{l}\text { Among the } \\
4 \text { groups }\end{array}$ & $\begin{array}{c}\text { ROS1 }^{+} \\
\text {vs. } \text { ALK }^{+}\end{array}$ & $\begin{array}{c}\text { ROS1 }^{+} \\
\text {vs. EGFR }\end{array}$ & $\begin{array}{l}\text { ROS }^{+} \\
\text {vs. WT }\end{array}$ \\
\hline Age (years) & $54.5(27-60)$ & $51.0(23-79)$ & $60.0(34-83)$ & $62.0(31-83)$ & $<0.001$ & 0.798 & 0.007 & 0.003 \\
\hline Male sex & $8(28.6)$ & $27(48.2)$ & $44(39.3)$ & $72(64.3)$ & $<0.001$ & 0.057 & 0.099 & 0.006 \\
\hline Smoking & $5(17.9)$ & $16(28.6)$ & $31(27.7)$ & $54(48.2)$ & 0.001 & 0.423 & 0.342 & 0.005 \\
\hline
\end{tabular}

Values are expressed as the median (range) or $\mathrm{n}(\%)$. ROS1, c-ros oncogene 1; ALK, anaplastic lymphoma kinase; EGFR, epidermal growth factor receptor; WT, wild-type.
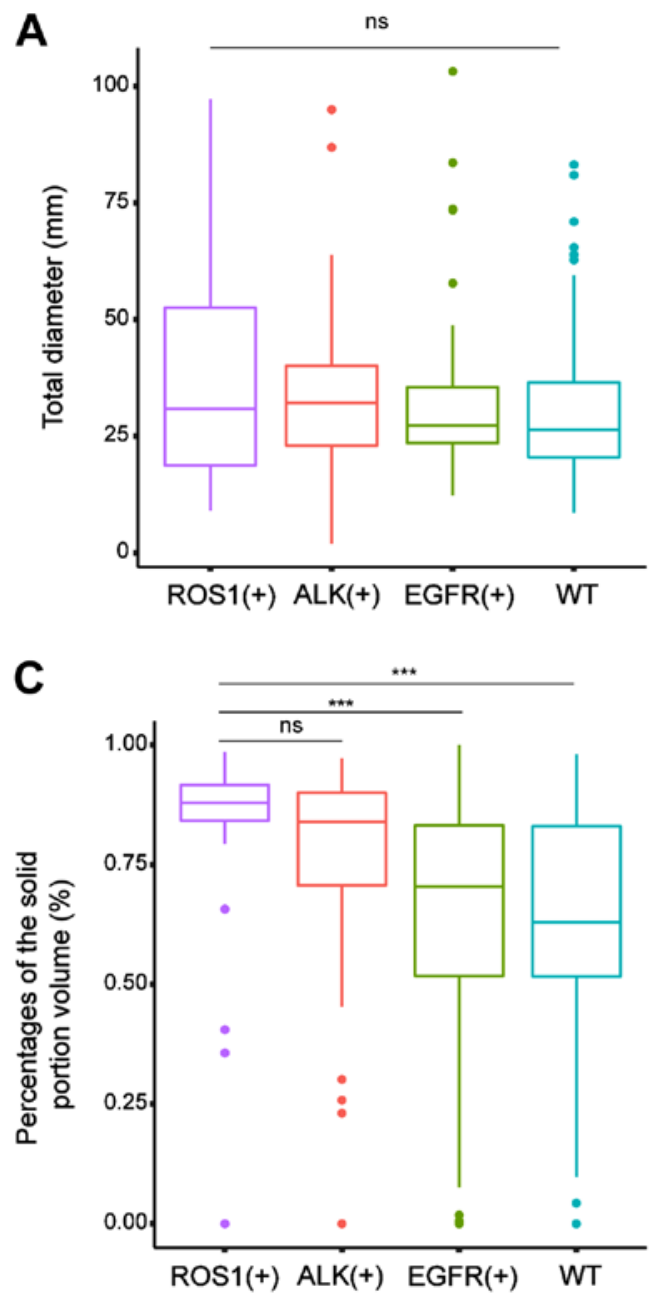
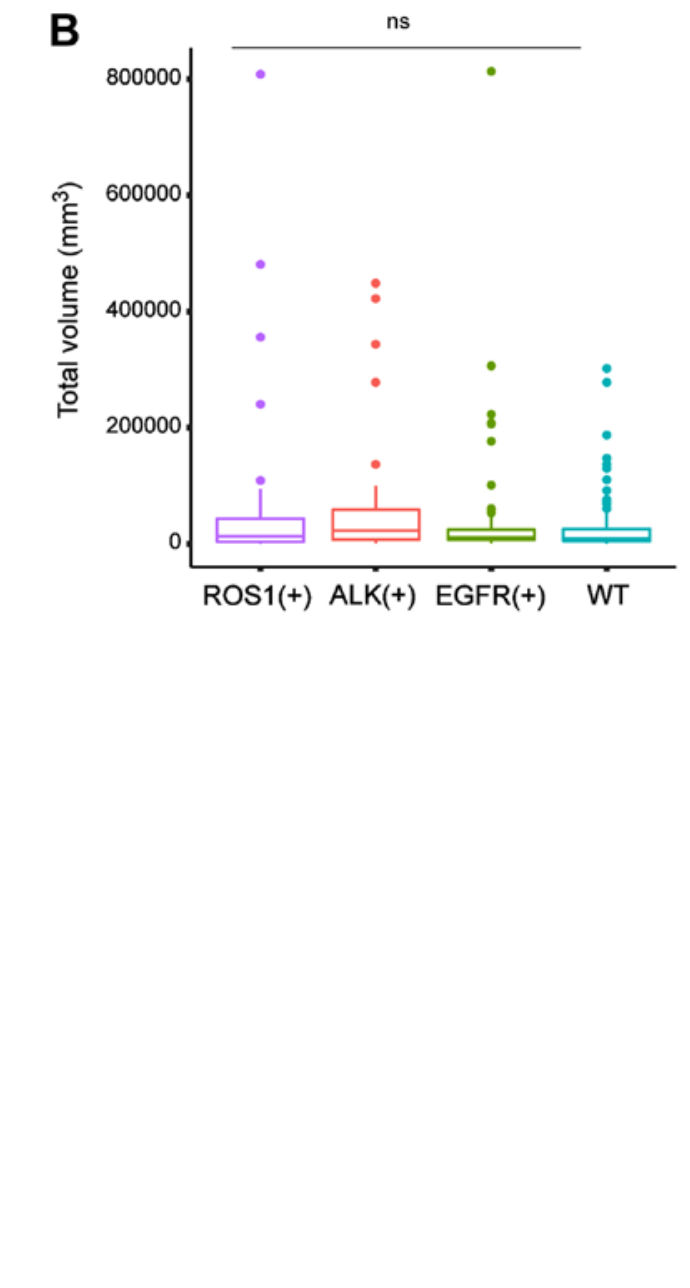

\begin{abstract}
Figure 4. Comparisons of the estimated volume and diameter of the total nodule $(\mathrm{tV}, \mathrm{tD})$ and the PSV across tumors with various genetic aberrations. (A and B) levels across tumors with various genetic aberrations. There was no difference in the median value of (A) the total diameter and (B) total volume among the four groups. (C) The median PSV was markedly higher in tumors with ROS1 mutations (87.9\%; IQR, 82.7-92.3\%) compared with those with EGFR changes (70.4\%; IQR 51.4-83.4\%; P<0.001) and those of the WT (63.0\%; IQR, 50.9-83.2\%; P<0.001). However, the difference in the median PSV between the $\mathrm{ROS1}^{+}$group and the $\mathrm{ALK}^{+}$group $(84.0 \%$; IQR, 70.3-90.0\%; $\mathrm{P}=0.251$ ) was not significant. In the boxplots, the horizontal lines indicate the median value, the boxes are the IQR, bars are the standard deviation and dots are the outliers. ${ }^{* * * *} \mathrm{P}<0.001$. ns, no significance; IQR, interquartile range; PSV, proportion of solid volume; ROS1, c-ros oncogene 1; ALK, anaplastic lymphoma kinase; EGFR, epidermal growth factor receptor; WT, wild-type.
\end{abstract}

to predict ROS1 or ALK rearrangement was drawn (Fig. 6B). The AUC was $0.702(95 \%$ CI, 0.631-0.773; $\mathrm{P}<0.001)$ at a cut-off value of 0.805 . When the Youden index was maximal, the sensitivity was 0.697 and the specificity was 0.702 .
Impact of genetic aberrations on CT imaging. A total of two radiologists independently reviewed the $\mathrm{CT}$ imaging and recorded the interpretations. The differences in interpretation between the two radiologists were as follows: Multiple 

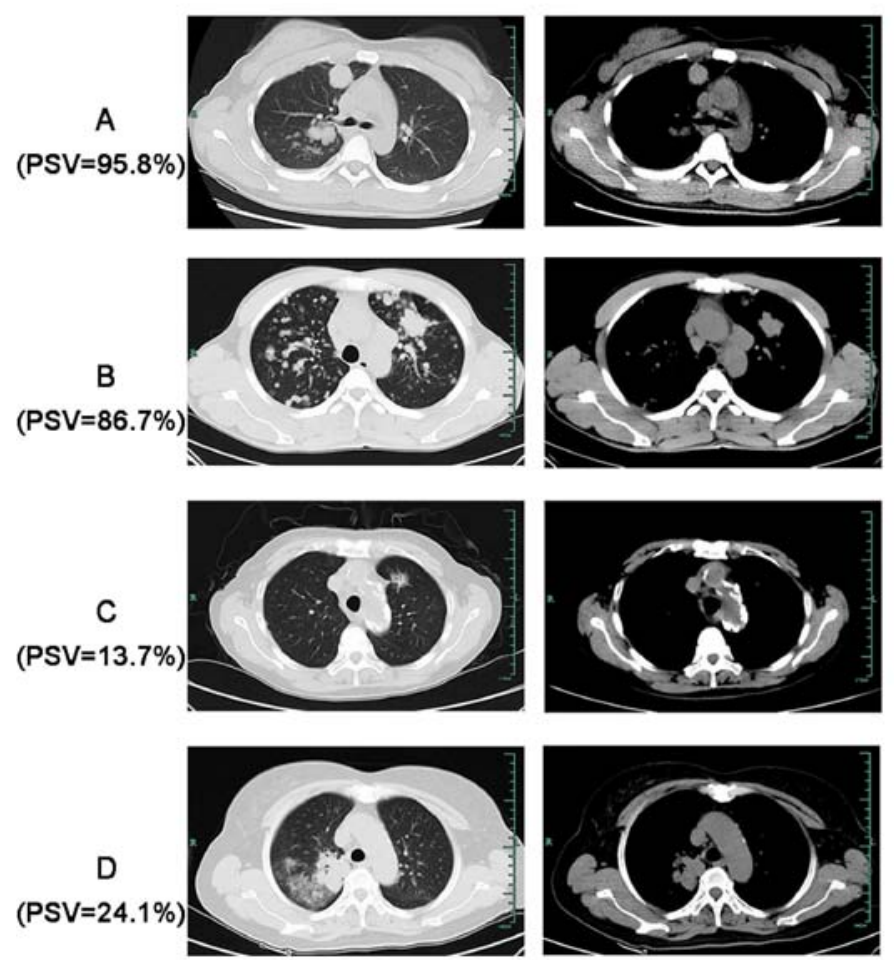

Figure 5. CT images in lung window (left panel) and mediastinal window (right) of four representative cases of lung adenocarcinoma with different genetic status. (A) A patient with ROS1 rearrangement with a PSV of 95.8\%. (B) A patient with ALK rearrangement with a PSV of 86.7\%. (C) A patient with EGFR mutation with a PSV of $13.7 \%$. (D) A patient with wild-type status and a PSV of 24.1\%. PSV, proportion of solid volume; ROS1, c-ros oncogene 1; ALK, anaplastic lymphoma kinase; EGFR, epidermal growth factor receptor.

lesions $(3 / 76 ; 3.9 \%)$, lobulated borders $(18 / 236 ; 7.6 \%)$, fine spiculated margins $(19 / 179 ; 10.6 \%)$, pleural retraction $(8 / 145$; $5.5 \%)$, bubble-like lucency or cavities (4/42; $9.5 \%)$, air bronchograms $(7 / 62 ; 11.3 \%)$ and liquefaction necrosis $(1 / 17 ; 5.9 \%)$. Disagreements were resolved by discussions to reduce the interobserver variability.

Table II summarises the final different features on CT imaging based on the various genetic aberrations. There were no differences in the frequency of multiple lesions, pleural retraction, fine spiculated margins, lobulated borders, bubble-like lucency or cavities, air bronchograms or liquefaction necrosis between tumors in the $\mathrm{ROS}^{+}$group and tumors in the $\mathrm{ALK}^{+}, \mathrm{EGFR}^{+}$or $\mathrm{WT}$ groups.

Univariate and multivariate analyses of clinical radiological parameters to predict ROSI/ALK-rearrangement by logistic regression. Given the similar clinical radiological characteristics between $\mathrm{ROSl}^{+}$tumors and $\mathrm{ALK}^{+}$lncRNAs, and the same first line recommended targeted treatment, univariate and multivariate analyses of clinical radiological parameters were performed to predict ROS1/ALK-rearrangement. All clinical parameters, including age, sex and smoking status, the quantitative volumetric parameters, including the total nodule diameter and PSV and all the aberrations on CT imaging were assessed via univariate logistic regression analysis. The results presented in Table III demonstrated that age, smoking history, total nodule diameter, PSV and existence of lobulated border, fine spiculated margin and pleural retraction were different $(\mathrm{P}<0.1)$ between ROS1/ALK-rearranged and non-ROS1/ALK-rearranged patients. These different parameters were subjected to multivariate logistic regression analysis, the results of which are also presented in Table III. Younger age and higher PSV values were independent predictors of ROS1/ALK rearrangements in the multivariate analysis. The correlation analysis between PSV and age suggested that the two factors were not correlated (Fig. S1). The ROC curve of the predictive model combined with age and PSV is presented in Fig. 6C, with an AUC of 0.785.

\section{Discussion}

In the present study, the clinical-radiological features of lung adenocarcinoma with certain genetic alterations were investigated. As compared with the WT group, the group of patients with ROS1 aberrations had a younger age, higher proportion of females and non-smokers and had a higher PSV. In the $\mathrm{ROS}^{+}$group, the PSV was significantly higher than that in the EGFR $^{+}$group. However, the clinical-radiological features of the $\mathrm{ROSl}^{+}$group and $\mathrm{ALK}^{+}$group were similar.

The clinical characteristics of patients with ROS1 rearrangement have been discussed in several previous studies (15-17,24-27). The age of ROS1-rearranged positive and non-ROS1-rearranged patients did not significantly differ in these previous reports $(15,16,24)$. However, the analysis of the present cohort revealed that in the $\mathrm{ROS}^{+}$group, the mean age was lower compared with that in the $\mathrm{EGFR}^{+}$and WT groups, a result consistent with those of Bergethon et al (25) and Chen et al (26). Female sex appears to be a clinical feature associated with an increased prevalence of ROS1 fusion. Most studies reported that ROS1 fusion was more frequently encountered in female patients compared with that in their male 
A

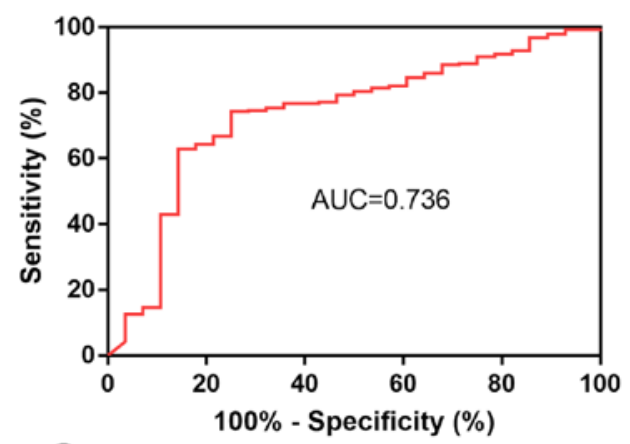

C

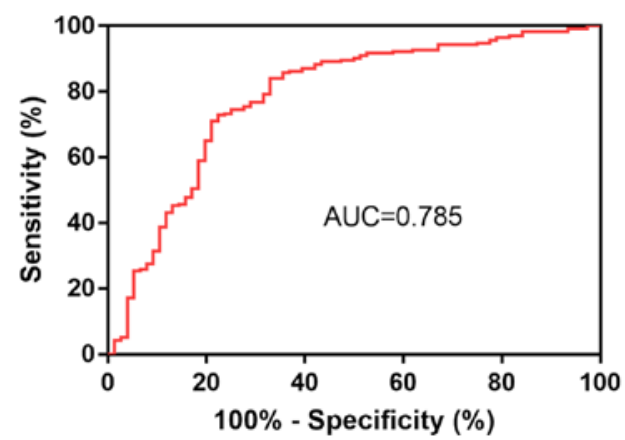

B

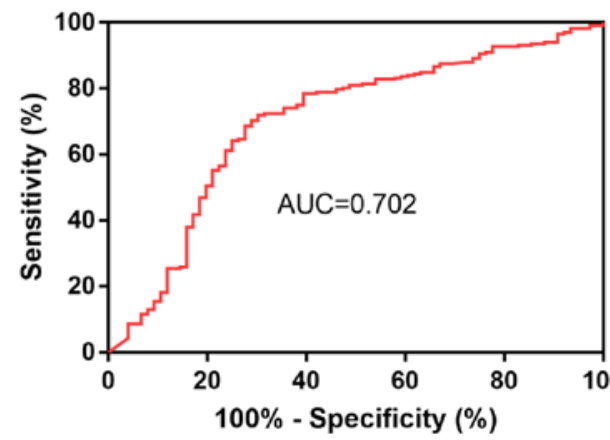

Figure 6. ROC curves of different parameters. (A) ROC curve of the percentage of the solid portion volume to predict ROS1 rearrangement. The AUC was 0.736 (95\% CI, 0.637-0.835; P<0.001). (B) ROC curve of the percentage of the solid portion volume to predict ROS1 or ALK rearrangements. The AUC was 0.702 (95\% CI: 0.631-0.773; P<0.001). (C) ROC curve of the combination of percentage of the solid portion volume and age to predict ROS1 or ALK rearrangements in patients with lung adenocarcinoma, with an AUC of 0.785. ROC, receiver operating characteristic; AUC, area under the curve; ROS1, c-ros oncogene 1; ALK, anaplastic lymphoma kinase.

counterparts $(24,27,28)$. Numerous studies have also confirmed an association of female sex with ALK rearrangement andEGFR mutation (11-13). The present study demonstrated an association between female sex and ROS1 fusion, with the proportion of female patients in the $\mathrm{ROS}^{+}$group being larger than that in the WT group (71.4\% vs. $35.7 \%$, respectively). ROS1 fusions were observed in smokers and never smokers, but a number of studies have demonstrated an association between this genetic aberration and light or never smokers $(24,25)$. However, other studies have revealed no association between smoking status and ROS1 fusion $(15,26,29)$. Most of the ROS1-rearranged individuals in the present study were never smokers $(23 / 28 ; 82.1 \%)$, with the number of never smokers being markedly higher than that in the WT group $(58 / 112 ; 51.8 \%)$.

Fukui et al (12) first reported solid radiological features in lung adenocarcinoma with ALK rearrangement. The mean tumor shadow disappearance rate (TDR) in their ALK-rearranged group was markedly less than that in nonALK-rearranged groups $(\mathrm{P}=0.0006)(12)$. In their and other previous studies, the TDR was defined as the ratio of the tumor area of the mediastinal window to that of the lung window $(12,22,30)$. TDR provides a limited representation of the proportion of the GGO area, as it is calculated from the GGO proportion at the maximal section of the tumor $(31,32)$ instead of the whole tumor. In the present study, data of the whole tumor nodule were first obtained to exactly calculate the PSV, which improved the accuracy of the calculation of the solid proportion. To the best of our knowledge, the present study also provided the first comparison of the volume of the solid component among the four primary genetic aberrations of lung adenocarcinomas.

The high PSV in ROS1 rearrangement tumors was consistent with that of ALK rearrangement tumors to a certain extent. It may be hypothesized that the similar radiological characteristics in these two groups reflect similar pathological features. A solid growth pattern and mucinous cribriform pattern were the two recognizable pathological findings in ALK-rearranged cancers $(33,34)$. Yoshida et al $(24)$ reported similar phenotypical features in tumors possessing either ALK and ROS1 genetic alterations, specifically, the presence of focal solid growth including signet-ring cells or cribriform architecture with abundant extracellular mucus in 53\% of ROS1 rearrangement cases. Go et al (15) also frequently observed solid and micropapillary patterns in at least the focal areas of tumors in $78.5 \%$ (11 of 14) of ROS1-rearranged cases.

Given the similar clinical-radiological features between $\mathrm{ROS}^{+}$tumors and $\mathrm{ALK}^{+}$tumors, multivariate analysis was also performed on the PSV and clinical features to predict ROS1 or ALK genetic changes in the present study. The results indicated a good predictive value of higher PSV and younger age for ROS1/ALK rearrangement in patients with lung adenocarcinoma. In addition to the excellent efficacy of crizotinib in ALK rearrangement lung adenocarcinomas, Shaw et al (8) demonstrated that ROS1-rearranged tumors were also sensitive to crizotinib treatment. Their study demonstrated that the median OS with crizotinib was 51.4 months $(95 \% \mathrm{CI}$ 
Table II. Genetic alterations and visual CT signs (morphological CT features).

\begin{tabular}{|c|c|c|c|c|c|c|c|c|}
\hline \multirow[b]{2}{*}{$\begin{array}{l}\text { Morphological } \\
\text { CT feature }\end{array}$} & \multicolumn{4}{|c|}{ Genetic alteration } & \multicolumn{4}{|c|}{ P-value } \\
\hline & $\begin{array}{l}\operatorname{ROS}^{+} \\
(n=28)\end{array}$ & $\begin{array}{l}\mathrm{ALK}^{+} \\
(\mathrm{n}=56)\end{array}$ & $\begin{array}{l}\mathrm{EGFR}^{+} \\
(\mathrm{n}=112)\end{array}$ & $\begin{array}{c}\text { WT } \\
(n=112)\end{array}$ & $\begin{array}{l}\text { Among the } \\
4 \text { groups }\end{array}$ & $\begin{array}{c}\operatorname{ROS}^{+} \\
\text {vs. } \mathrm{ALK}^{+}\end{array}$ & $\begin{array}{c}\operatorname{ROS}^{+} \\
\text {vs. EGFR }\end{array}$ & $\begin{array}{l}\text { ROS1 } 1^{+} \\
\text {vs. WT }\end{array}$ \\
\hline Multiple lesions & $5(17.9)$ & $20(35.7)$ & $26(23.2)$ & $25(22.3)$ & 0.184 & 0.129 & 0.620 & 0.798 \\
\hline Lobulated border & $21(75.0)$ & $35(62.5)$ & $88(78.6)$ & $92(82.1)$ & 0.038 & 0.329 & 0.799 & 0.425 \\
\hline Fine spiculated margin & $16(57.1)$ & $23(41.1)$ & $74(66.1)$ & $66(58.9)$ & 0.022 & 0.174 & 0.387 & 1 \\
\hline Pleural retraction & $11(39.3)$ & $14(25.0)$ & $60(53.6)$ & $60(53.6)$ & 0.001 & 0.210 & 0.208 & 0.208 \\
\hline Bubble-like lucency or cavities & $4(14.3)$ & $3(5.4)$ & $22(19.6)$ & $13(11.6)$ & 0.069 & 0.215 & 0.599 & 0.747 \\
\hline Air bronchogram & $3(10.7)$ & $9(16.1)$ & $29(25.9)$ & $21(18.8)$ & 0.207 & 0.743 & 0.130 & 0.408 \\
\hline Liquefaction necrosis & $1(3.6)$ & $2(3.6)$ & $9(8.0)$ & $5(4.5)$ & 0.530 & 1 & 0.687 & 1 \\
\hline
\end{tabular}

Values are expressed as n (\%). ROS1, c-ros oncogene 1; ALK, anaplastic lymphoma kinase; EGFR, epidermal growth factor receptor; WT, wild-type.

Table III. Univariate and multivariate analyses of clinical-radiological parameters to predict ROS1/ALK rearrangement.

\begin{tabular}{|c|c|c|c|c|c|c|}
\hline \multirow[b]{2}{*}{ Clinical-radiological factors } & \multicolumn{3}{|c|}{ Univariate analysis $^{\mathrm{a}}$} & \multicolumn{3}{|c|}{ Multivariate analysis ${ }^{\mathrm{a}}$} \\
\hline & HR & $95 \% \mathrm{CI}$ & P-value & HR & $95 \% \mathrm{CI}$ & P-value \\
\hline Sex & 0.741 & $0.440-1.249$ & 0.261 & - & - & - \\
\hline Age & 0.939 & $0.916-0.962$ & $<0.001$ & 0.946 & $0.921-0.971$ & $<0.001$ \\
\hline Smoking history (smoker) & 0.606 & $0.341-1.078$ & 0.096 & 0.691 & $0.366-1.303$ & 0.253 \\
\hline Total nodule diameter & 1.018 & $1.002-1.034$ & 0.023 & 0.998 & $0.980-1.017$ & 0.841 \\
\hline PSV & 17.084 & $4.181-69.812$ & $<0.001$ & 16.545 & $3.449-79.374$ & $<0.001$ \\
\hline Multiple lesions & 1.598 & $0.900-2.836$ & 0.109 & - & - & - \\
\hline Lobulated border & 0.476 & $0.268-0.844$ & 0.011 & 0.676 & $0.334-1.372$ & 0.278 \\
\hline Fine spiculated margin & 0.486 & $0.287-0.821$ & 0.007 & 0.805 & $0.429-1.509$ & 0.498 \\
\hline Pleural retraction & 0.361 & $0.206-0.631$ & $<0.001$ & 0.537 & $0.278-1.036$ & 0.064 \\
\hline Bubble-like lucency or cavities & 0.571 & $0.242-1.345$ & 0.249 & - & - & - \\
\hline Air bronchogram & 0.683 & $0.342-1.363$ & 0.325 & - & - & - \\
\hline Liquefaction necrosis & 0.640 & $0.179-2.290$ & 0.492 & - & - & - \\
\hline
\end{tabular}

${ }^{a}$ Univariate and Multivariate analysis was performed by using logistic regression. PSV, portion of solid volume; HR, hazard ratio; CI, confidence interval.

29.3 months to not reached), the PFS was 19.3 months (95\% CI 15.2-39.1 months) and the survival probability at 12,24,36 and 48 months was 79, 67, 53 and 51\%, respectively. As both ROS1 rearrangement NSCLCs and ALK rearrangement NSCLCs benefit from treatment with crizotinib, it is important to distinguish ROS1/ALK rearrangement from EGFR mutation or WT NSCLCs. Furthermore, given the similar treatment and the clinical-imaging characteristics, it may be strongly recommended that a young patient with a high-PSV tumor should be tested preferentially for ROS1 and ALK rearrangements in the event of limited tissue samples or for financial sources.

The present study provides clinical data on a relatively large number of ROS1-rearranged patients and is the first demonstration of different imaging findings between ROS1-rearranged, ALK-rearranged, EGFR-mutated and WT lung adenocarcinomas. One limitation of the present study was that the CT images were obtained by two different systems, and most of the CT images were reconstructed with $5.0 \mathrm{~mm}$ and not $1.0 \mathrm{~mm}$ thickness. Another limitation was that the ALK-rearranged, EGFR-mutated and WT groups did not include all patients available but they were selected from them by a randomization procedure. This may have led to a slight selection bias for not including all the patients in the present study.

In conclusion, a solid pattern with a higher PSV on CT images was determined as the primary characteristic of tumors with ROS1-rearrangement in contrast to those with EGFR mutation and WT tumors. However, the solid CT characteristics between the $\mathrm{ROS}^{+}$group and $\mathrm{ALK}^{+}$group were similar. PSV and age were independent predictors for ROS1/ALK rearrangement. Future prospective studies with unified methods and larger sample sizes are necessary to confirm the present results. 


\section{Acknowledgements}

Not applicable.

\section{Funding}

This study was supported by grants from the Key Research and Development Program of Zhejiang Province, China (grant no. 2019C03042 to JYiZ), the Zhejiang Provincial Natural Science Foundation (grant no. LGF19H160031 to JZ) and the National Natural Science Foundation of China (grant no. 81972179 to JYaZ). The funders had no role in the study design, participant recruitment, data collection, data analysis, data interpretation, manuscript preparation or the decision to submit the paper for publication.

\section{Availability of data and materials}

The datasets used and/or analyzed during the current study are available from the corresponding author on reasonable request.

\section{Authors' contributions}

JZ, JYaZ and JYiZ were responsible for the conception and design of the study. JL and JX did the quantitative volumetric assessments. KS, BW and WD did the genetic analysis. HC was responsible for data collection and analysis. All authors contributed significantly to data collection, data analysis, interpretation of the data and manuscript writing. All authors read and approved the final manuscript.

\section{Ethics approval and consent to participate}

The present study was approved by the Ethics Committee of the First Affiliated Hospital of Zhejiang University (Hangzhou, China; approval no. IIT20200137A) who waived the requirement for informed consent, as it was a retrospective study.

\section{Patient consent for publication}

Not applicable.

\section{Competing interests}

The authors declare that they have no competing interests.

\section{References}

1. Lynch TJ, Bell DW, Sordella R, Gurubhagavatula S, Okimoto RA, Brannigan BW, Harris PL, Haserlat SM, Supko JG, Haluska FG, et al: Activating mutations in the epidermal growth factor receptor underlying responsiveness of non-small-cell lung cancer to gefitinib. N Engl J Med 350: 2129-2139, 2004.

2. Paez JG, Janne PA, Lee JC, Tracy S, Greulich H, Gabriel S, Herman P, Kaye FJ, Lindeman N, Boggon TJ, et al: EGFR mutations in lung cancer: Correlation with clinical response to gefitinib therapy. Science 304: 1497-1500, 2004.

3. Soda M, Choi YL,Enomoto M, Takada S, Yamashita Y, Ishikawa S, Fujiwara S, Watanabe H, Kurashina K, Hatanaka $\mathrm{H}$, et al: Identification of the transforming EML4-ALK fusion gene in non-small-cell lung cancer. Nature 448: 561-566, 2007.
4. Rikova K, Guo A, Zeng Q, Possemato A, Yu J, Haack H, Nardone J, Lee K, Reeves C, Li Y, et al: Global survey of phosphotyrosine signaling identifies oncogenic kinases in lung cancer. Cell 131: 1190-1203, 2007.

5. Rodig SJ and Shapiro GI: Crizotinib, a small-molecule dual inhibitor of the c-Met and ALK receptor tyrosine kinases. Curr Opin Investig Drugs 11: 1477-1490, 2010.

6. Cui JJ, Tran-Dube M, Shen H, Nambu M, Kung PP, Pairish M, Jia L, Meng J, Funk L, Botrous I, et al: Structure based drug design of crizotinib (PF-02341066), a potent and selective dual inhibitor of mesenchymal-epithelial transition factor (c-MET) kinase and anaplastic lymphoma kinase (ALK). J Med Chem 54: 6342-6363, 2011

7. Shaw AT, Kim DW, Nakagawa K, Seto T, Crinó L, Ahn MJ, De Pas T, Besse B, Solomon BJ, Blackhall F, et al: Crizotinib versus chemotherapy in advanced ALK-positive lung cancer. N Engl J Med 368: 2385-2394, 2013.

8. Shaw AT, Riely GJ, Bang YJ, Kim DW, Camidge DR, Solomon BJ, Varella-Garcia M, Iafrate AJ, Shapiro GI, Usari T, et al: Crizotinib in ROS1-rearranged advanced non-small-cell lung cancer (NSCLC): Updated results, including overall survival, from PROFILE 1001. Ann Oncol 30: 1121-1126, 2019.

9. Inamura $K$, Takeuchi $K$, Togashi $Y$, Nomura K, Ninomiya $H$, Okui M, Satoh Y, Okumura S, Nakagawa K, Soda M, et al: EML4-ALK fusion is linked to histological characteristics in a subset of lung cancers. J Thorac Oncol 3: 13-17, 2008.

10. Wong DW, Leung EL, So KK, Tam IY, Sihoe AD, Cheng LC, Ho KK, Au JS, Chung LP, Pik Wong M, et al: The EML4-ALK fusion gene is involved in various histologic types of lung cancers from nonsmokers with wild-type EGFR and KRAS. Cancer 115: 1723-1733, 2009.

11. Takahashi T, Sonobe M, Kobayashi M, Yoshizawa A, Menju T, Nakayama E, Mino N, Iwakiri S, Sato K, Miyahara R, et al: Clinicopathologic features of non-small-cell lung cancer with EML4-ALK fusion gene. Ann Surg Oncol 17: 889-897, 2010.

12. Fukui T, Yatabe Y, Kobayashi Y, Tomizawa K, Ito S, Hatooka S, Matsuo K and Mitsudomi T: Clinicoradiologic characteristics of patients with lung adenocarcinoma harboring EML4-ALK fusion oncogene. Lung Cancer 77: 319-325, 2012.

13. Zhou JY, Zheng J, Yu ZF, Xiao WB, Zhao J, Sun K, Wang B, Chen X, Jiang LN, Ding W and Zhou JY: Comparative analysis of clinicoradiologic characteristics of lung adenocarcinomas with ALK rearrangements or EGFR mutations. Eur Radiol 25: 1257-1266, 2015.

14. Choi H, Paeng JC, Kim DW, Lee JK, Park CM, Kang KW, Chung JK and Lee DS: Metabolic and metastatic characteristics of ALK-rearranged lung adenocarcinoma on FDG PET/CT. Lung Cancer 79: 242-247, 2013.

15. Go H, Kim DW, Kim D, Keam B, Kim TM, Lee SH, Heo DS, Bang YJ and Chung DH: Clinicopathologic analysis of ROS1-rearranged non-small-cell lung cancer and proposal of a diagnostic algorithm. J Thorac Oncol 8: 1445-1450, 2013.

16. Warth A, Muley T, Dienemann H, Goeppert B, Stenzinger A, Schnabel PA, Schirmacher P, Penzel R and Weichert W: ROS1 expression and translocations in non-small-cell lung cancer: Clinicopathological analysis of 1478 cases. Histopathology 65: 187-194, 2014.

17. Digumarthy SR, Mendoza DP, Lin JJ, Chen T, Rooney MM, Chin E, Sequist LV, Lennerz JK, Gainor JF and Shaw AT: Computed tomography imaging features and distribution of metastases in ROS1-rearranged non-small-cell lung cancer. Clin Lung Cancer 21: 153-159.e3, 2020.

18. Detterbeck FC, Boffa DJ and Tanoue LT: The new lung cancer staging system. Chest 136: 260-271, 2009.

19. Shan L, Lian F, Guo L, Qiu T, Ling Y, Ying J and Lin D: Detection of ROS1 gene rearrangement in lung adenocarcinoma: Comparison of IHC, FISH and real-time RT-PCR. PLoS One 10: $\mathrm{e} 0120422,2015$.

20. Lee HJ, Kim YT, Kang CH, Zhao B, Tan Y, Schwartz LH, Persigehl T, Jeon YK and Chung DH: Epidermal growth factor receptor mutation in lung adenocarcinomas: Relationship with CT characteristics and histologic subtypes. Radiology 268: 254-264, 2013.

21. Hansell DM, Bankier AA, MacMahon H, McLoud TC, Muller NL and Remy J: Fleischner Society: Glossary of terms for thoracic imaging. Radiology 246: 697-722, 2008.

22. Ikehara M, Saito H, Kondo T, Murakami S, Ito H, Tsuboi M, Oshita F, Noda K, Nakayama H, Yokose T, et al: Comparison of thin-section CT and pathological findings in small solid-density type pulmonary adenocarcinoma: Prognostic factors from CT findings. Eur J Radiol 81: 189-194, 2012. 
23. Quaia E, Baratella E, Pizzolato R, Bussani R and Cova MA: Radiological-pathological correlation in intratumoural tissue components of solid lung tumours. Radiol Med 114: 173-189, 2009 (In Italian).

24. Yoshida A, Kohno T, Tsuta K, Wakai S, Arai Y, Shimada Y, Asamura H, Furuta K, Shibata T and Tsuda H: ROS1-rearranged lung cancer: A clinicopathologic and molecular study of 15 surgical cases. Am J Surg Pathol 37: 554-562, 2013.

25. Bergethon K, Shaw AT, Ou SH, Katayama R, Lovly CM, McDonald NT, Massion PP, Siwak-Tapp C, Gonzalez A, Fang R, et al: ROS1 rearrangements define a unique molecular class of lung cancers. J Clin Oncol 30: 863-870, 2012.

26. Chen YF, Hsieh MS, Wu SG, Chang YL, Shih JY, Liu YN, Tsai MF, Tsai TH, Yu CJ, Yang JC and Yang PC: Clinical and the prognostic characteristics of lung adenocarcinoma patients with ROS1 fusion in comparison with other driver mutations in East Asian populations. J Thorac Oncol 9: 1171-1179, 2014.

27. Zhu Q, Zhan P, Zhang X, Lv T and Song Y: Clinicopathologic characteristics of patients with ROS1 fusion gene in non-small cell lung cancer: A meta-analysis. Transl Lung Cancer Res 4: 300-309, 2015.

28. Zhu YC, Zhang XG, Lin XP, Wang WX, Li XF, Wu LX, Chen HF, $\mathrm{Xu} \mathrm{CW}$ and Du KQ: Clinicopathological features and clinical efficacy of crizotinib in Chinese patients with ROS1-positive non-small cell lung cancer. Oncol Lett 17: 3466-3474, 2019.
29. Cai W, Li X, Su C, Fan L, Zheng L, Fei K, Zhou C, Manegold C and Schmid-Bindert G: ROS1 fusions in Chinese patients with non-small-cell lung cancer. Ann Oncol 24: 1822-1827, 2013.

30. Shimizu K, Yamada K, Saito H, Noda K, Nakayama H, Kameda Y and Nakata K: Surgically curable peripheral lung carcinoma: Correlation of thin-section CT findings with histologic prognostic factors and survival. Chest 127: 871-878, 2005.

31. Okada M, Nishio W, Sakamoto T, Uchino K and Tsubota N: Discrepancy of computed tomographic image between lung and mediastinal windows as a prognostic implication in small lung adenocarcinoma. Ann Thorac Surg 76: 1828-1832, 2003.

32. Takamochi K, Nagai K, Yoshida J, Suzuki K, Ohde Y, Nishimura M, Sasaki S and Nishiwaki Y: Pathologic NO status in pulmonary adenocarcinoma is predictable by combining serum carcinoembryonic antigen level and computed tomographic findings. J Thorac Cardiovasc Surg 122: 325-330, 2001.

33. Yoshida A, Tsuta K, Nakamura H, Kohno T, Takahashi F, Asamura H, Sekine I, Fukayama M, Shibata T, Furuta K and Tsuda H: Comprehensive histologic analysis of ALK-rearranged lung carcinomas. Am J Surg Pathol 35: 1226-1234, 2011.

34. Rodig SJ, Mino-Kenudson M, Dacic S, Yeap BY, Shaw A, Barletta JA, Stubbs H, Law K, Lindeman N, Mark E, et al: Unique clinicopathologic features characterize ALK-rearranged lung adenocarcinoma in the western population. Clin Cancer Res 15: 5216-5223, 2009. 